\title{
molecules
}

ISSN 1420-3049

www.mdpi.com/journal/molecules

Article

\section{In Vivo and In Vitro Anti-Tumor Effects of Fungal Extracts}

\section{Hung-Tsung Wu ${ }^{1,2}$, Feng-Hwa Lu ${ }^{2}$, Yu-Chu Su ${ }^{3}$, Horng-Yih Ou ${ }^{4}$, Hao-Chang Hung ${ }^{4}$, Jin-Shang $\mathrm{Wu}^{2}$, Yi-Ching Yang ${ }^{2}$ and Chih-Jen Chang ${ }^{1,2, *}$}

1 Research Center of Herbal Medicine, New Drugs and Nutritional Supplements, Research and Services Headquarters, National Cheng Kung University, Tainan 70403, Taiwan;

E-Mail: microbe0905702@yahoo.com.tw

2 Department of Family Medicine, National Cheng Kung University Medical College and Hospital, Tainan 70403, Taiwan; E-Mails: fhlu@mail.ncku.edu.tw (F.-H.L.); jins@mail.ncku.edu.tw (J.-S.W.); yiching@mail.ncku.edu.tw (Y.-C.Y.)

3 Institute of Basic Medical Sciences, College of Medicine, National Cheng Kung University, Tainan 70403, Taiwan; E-Mail: horseofblackchu@gmail.com

4 Department of Internal Medicine, National Cheng Kung University Medical College and Hospital, Tainan 70403, Taiwan; E-Mails: wahoryi@mail.ncku.edu.tw (H.-Y.O.); haochang.hung@gmail.com (H.-C.H.)

* Author to whom correspondence should be addressed: E-Mail: changcj.ncku@gmail.com; Tel.: +886-6-235-3535 (ext. 5210); Fax: +886-6-275-4243.

Received: 7 January 2014; in revised form: 6 February 2014 / Accepted: 20 February 2014 / Published: 21 February 2014

\begin{abstract}
Fungal extracts are extensively used as nutritional supplements in Far-Eastern Asia. In this study, we aimed to evaluate the anti-cancer activities of some different fungal species against different cancer cell lines. The water or ethanol extracts of Fomitopsis pinicola (F. pinicola), Ganoderma sinense, Fomitopsis officinalis, Polyporus melanopus, and Taiwanofungus camphorates were used to evaluate the anti-cancer activities in various cancer cells. We found that all of the fungi ethanol extracts used in this study exert anti-cancer activities in vitro, whereas water extracts show lower inhibitory activities as determined by 3-(4,5-methylthiazol-2-yl)-2,5-diphenyltetrazolium bromide assays. Among the tested fungi species, $F$. pinicola ethanol extract exerts the most significant anti-cancer activity (growth inhibitory ratio $82.8 \%, p<0.001$ ) by increasing cell apoptosis. Moreover, $F$. pinicola ethanol extract significantly decreased tumor size (tumor growth inhibitory ratio $54 \%, p<0.05)$ and increased the lifespan in mice bearing sarcoma-180 tumors. Taken together, this is the first study indicating the anti-tumor effect of $F$. pinicola in vivo and
\end{abstract}


in vitro. $F$. pinicola ethanol extract induces cell apoptosis to exert a significant anti-tumor activity, with potential to be a new alternative anti-tumor medicine.

Keywords: apoptosis; cancer; $F$. pinicola; sarcoma-180 cells; tumors

\section{Introduction}

Fungi species, including reishi mushrooms are attractive sources of physiologically functional foods and drug precursors, displaying a wide range of pharmacological activities such as anticancer, anti-inflammation and immunomodulatory effects [1]. A wide range of fungal species are extensively used as nutritional supplements in Asia and are being increasingly used in Western countries too in conjunction with or in place of allopathic medicines [2]. Fungal extracts produce a variety of biologically active compounds and can therefore exert multiple biological functions. Increased evidence indicates that fungal extract consumption may protect against certain types of cancers, specifically gastrointestinal and breast cancer [3-5]. However, the efficacy of different fungal species in curing cancer and as preventive treatments remains as questionable and has not been scientifically evaluated.

Fomitopsis pinicola ( $F$. pinicola) is a brown-rot fungus, that grows on coniferous and broad-leaved trees and is widespread in Asia and Europe [6]. It belongs to the Polyporaceae, traditionally categorized as reishi fungus in Far-Eastern Asia. The dry fruiting bodies of different Fomitopsis species have been used in folk medicine as haemostatics and anti-inflammation agents [7,8]. In addition, F. pinicola has been traditionally used as an anti-diabetic material in Korean folk medicine [9] and is considered a nontoxic mushroom in Europe [7]. The principle components of $F$. pinicola, such as triterpenes [10], steroids [7], and a heterogalactan [11] have been shown to exert medicinal effects, including antimicrobial action [7] and the inhibition of cyclooxygenase activity [10]. However, to the best of our knowledge, no report is available on the effect of $F$. pinicola on cancers.

In this article, we used different fungi water or ethanol extracts, including $F$. pinicola, Ganoderma sinense (G. sinense), Fomitopsis officinalis (F. officinalis), Polyporus melanopus (P. melanopus), Taiwanofungus camphorates (T. camphorates) to evaluate the corresponding anti-cancer activities in different cancer cell lines. We also clarified the possible mechanisms of $F$. pinicola in anti-cancer activity in vivo and in vitro.

\section{Results and Discussion}

\subsection{Different Fungi Extracts Exhibit Anti-Tumor Activities in Different Cancer Cells}

The number of new cancer cases each year is projected to rise worldwide by about $70 \%$ by 2030 due to demographic changes alone, with the largest increases in the lower-income countries. Lung, liver, colorectal and breast cancers are the most commonly diagnosed in males and females respectively, and these cancers also represent the most frequent types of cancer related deaths. Thus, medical advances in disease treatment are an issue at a later stage and should be made available globally [12]. In order to evaluate the anti-cancer activity of different fungal species, different cancer cells lines, including Homo sapiens hepatoma (HepG2), lung cancer (A549), colorectal cancer 
(HCT-116), breast cancer (MDA-MB-231) cells and Mus musculus sarcoma (S-180) cells were treated with same concentration at $50 \mu \mathrm{g} / \mathrm{mL}$ of the water or ethanol extracts of different fungi (Table 1). The tested fungal samples in the study, including $G$. sinense and T. camphorates have been reported to exert anti-cancer activities. $G$. sinense has an antiproliferation effect on tumors through both the apoptosis pathway and cell cycle arrest effects, and besides triterpenoids, some other compounds such as sterols and nucleosides may contribute to these activities [13]. Triterpenoids isolated from T. camphorates are considered to be potential anticancer agents [14]. Among the tested fungal samples, $F$. officinalis, $P$. melanopus and $F$. pinicola were not reported to have effects on cancer cells, so this is the first report indicating that $F$. officinalis, $P$. melanopus, and $F$. pinicola exert anti-cancer effects in vitro. Water extracts of the different fungi species exert more moderate anti-cancer activities than that of ethanol extracts. Some of the fungi species water extracts even shows no inhibitory effect on HepG2 and A549 cells. In contrast to water extracts, ethanol extracts of different fungal species show significant anti-cancer activities. In addition, among the various fungal ethanol extracts, $F$. pinicola ethanol extract exerts the strongest inhibitory effect on the tested cancer cell lines. To the best of our knowledge, this is the first report indicated that the ethanol extract of $F$. pinicola shows an anti-tumor activity, although it is extensively used in Asia and Europe as a non-toxic anti-diabetes fungus [9].

Table 1. Growth-inhibition effect of different reishi mushroom extracts on different cancer cell lines. Mouse sarcoma 180 cells (S-180), human hepatoma (HepG2), lung cancer (A549), colon cancer (HCT-116) and breast cancer (MDA-MB-231) cells were treated with different fungus water or ethanol extracts at a dose of $50 \mu \mathrm{g} / \mathrm{mL}$ for $24 \mathrm{~h}$. The viability of the cells was determined by MTT assay. Data were presented as mean \pm S.E.M, and obtained from three independent experiments with four replicates for each experiment. $* p<0.05,{ }^{* *} p<0.01$ and $* * * p<0.001$ compared with the cell viability of control group which was set as $100 \%$.

\begin{tabular}{cccccc}
\hline & S-180 & HepG2 & A549 & HCT-116 & MDA-MB-231 \\
\hline F. pinicola & & & & & \\
Water extract & $78.9 \pm 5.6 *$ & $96.6 \pm 5.8$ & $97.0 \pm 2.4$ & $62.5 \pm 8.5 * *$ & $60.1 \pm 7.2^{* *}$ \\
EtOH extract & $17.2 \pm 3.4 * * *$ & $28.7 \pm 7.5 * * *$ & $7.1 \pm 3.2 * * *$ & $12.1 \pm 2.9 * * *$ & $34.1 \pm 5.1 * * *$ \\
G. sinense & & & & \\
Water extract & $47.7 \pm 3.5 * *$ & $94.6 \pm 3.5$ & $96.9 \pm 2.3$ & $72.1 \pm 5.7 *$ & $61.3 \pm 6.9 * *$ \\
EtOH extract & $31.2 \pm 10.2 * * *$ & $41.2 \pm 10.2 * *$ & $80.3 \pm 7.6 *$ & $14.7 \pm 2.1 * * *$ & $28.5 \pm 4.8^{* * *}$ \\
F. officinalis & & & & \\
Water extract & $64.0 \pm 4.9 * *$ & $98.9 \pm 0.9$ & $97.9 \pm 1.4$ & $20.6 \pm 6.2 * * *$ & $60.8 \pm 8.8^{* *}$ \\
EtOH extract & $34.1 \pm 9.1 * *$ & $31.1 \pm 5.1 * *$ & $62.0 \pm 4.4 *$ & $15.7 \pm 4.0 * * *$ & $28.8 \pm 1.1 * * *$ \\
P. melanopus & & & & \\
Water extract & $61.7 \pm 8.1 * *$ & $99.9 \pm 0.1$ & $97.7 \pm 0.9$ & $48.4 \pm 4.6 * *$ & $73.6 \pm 4.9 *$ \\
EtOH extract & $33.3 \pm 7.7 * * *$ & $31.5 \pm 2.7 * *$ & $82.5 \pm 7.5 *$ & $16.0 \pm 3.3 * * *$ & $28.7 \pm 5.8 * * *$ \\
T. camphoratus & & & & \\
Water extract & $98.2 \pm 5.6$ & $44.8 \pm 5.6 * *$ & $94.6 \pm 2.5$ & $72.5 \pm 6.7 *$ & $51.1 \pm 4.2 * *$ \\
EtOH extract & $48.5 \pm 3.2 * *$ & $36.2 \pm 6.2 * *$ & $9.8 \pm 2.4 * * *$ & $12.9 \pm 1.9 * * *$ & $29.1 \pm 3.6 * * *$ \\
\hline
\end{tabular}




\subsection{Ethanol Extract of F. pinicola Significantly Decreases S-180 Cell Viability}

We then investigated the half maximal inhibitory concentration $\left(\mathrm{IC}_{50}\right)$ values of different $F$. pinicola extracts on S-180 cells (Figure 1). Ethanol extract of $F$. pinicola shows stronger inhibitory effect on cancer cells $\left(\mathrm{IC}_{50}=7.4 \mu \mathrm{g} / \mathrm{mL}\right)$ than a $50 \%$ ethanol extract $\left(\mathrm{IC}_{50}=12.2 \mu \mathrm{g} / \mathrm{mL}\right)$, whereas the inhibitory effect of water extract was weaker than that of the ethanol extracts $\left(\mathrm{IC}_{50}>100 \mu \mathrm{g} / \mathrm{mL}\right)$. This result implies that the main components that contribute to the anti-tumor effects of $F$. pinicola may be hydrophobic. In addition, we found that $F$. pinicola ethanol extract inhibited S-180 cell growth at $12 \mathrm{~h}$ and significant cell death was observed at $24 \mathrm{~h}$ after treatment, implying the mediation of programmed cell death (Figure 2). The anticancer activities of fungi are mainly linked to the modulation of the immune system by branched polysaccharides (glucans), glycoproteins or peptide/protein-bound polysaccharides [15,16]. Moreover, mushrooms contain minerals, vitamins (e.g., thiamin, riboflavin, ascorbic acid, and vitamin D), amino acids, and other organic compounds [17]. Some of these natural mushroom compounds have demonstrated specific activity against aberrantly activated signaling pathways in cancer cells and were able to modulate specific molecular targets in the cell function including cell proliferation, cell survival and angiogenesis [18]. F. pinicola has been studied over the last years and a number of triterpenic compounds have been isolated [10,19], many of them possessing antimicrobial and anti-inflammatory activities. In this study, we found that $F$. pinicola ethanol extract also exerts an effect on anti-tumor.

Figure 1. Anti-tumor effect of different $F$. pinicola extracts on S-180 cells. Sarcoma S-180 cells were treated with different $F$. pinicola extracts at indicated doses for $24 \mathrm{~h}$. Cells were then incubated with $0.2 \mathrm{mg} / \mathrm{mL}$ MTT in culture medium for $4 \mathrm{~h}$. MTT reagent was discarded and DMSO was added. The absorbance was measured at the wavelength of $570 \mathrm{~nm}$. The data is expressed as means \pm S.E.M. and obtained from three independent experiments with four replicates for each experiment. * $p<0.05$, ** $p<0.01$ and *** $p<0.001$ compared with the control group.

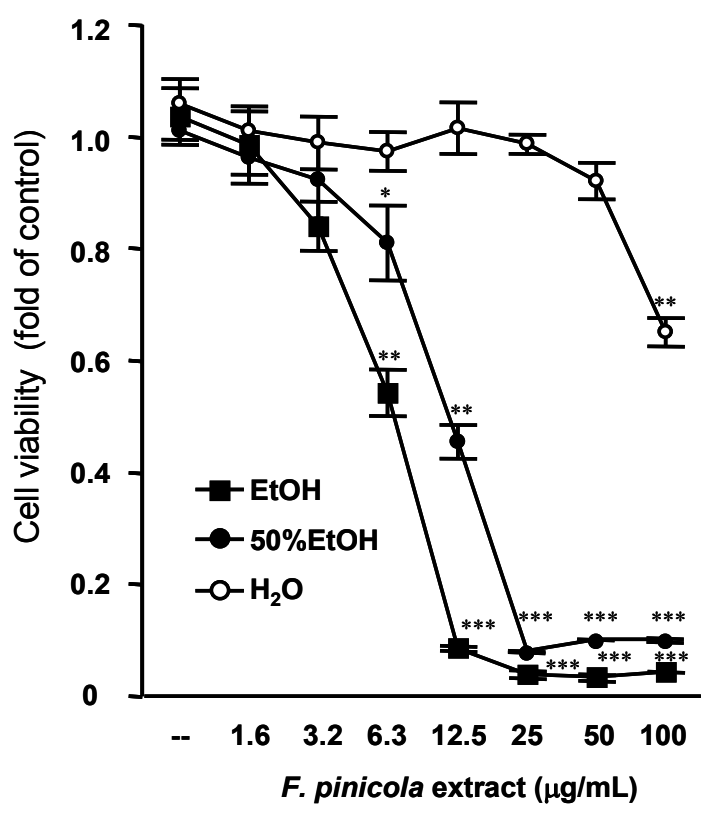


Figure 2. Ethanol extract of $F$. pinicola inhibits S-180 cells proliferation in a time-dependent manner. Sarcoma S-180 cells were treated with $F$. pinicola ethanol extract at a dose of $12.5 \mu \mathrm{g} / \mathrm{mL}$ for various durations as indicated. Cells were then incubated with $0.2 \mathrm{mg} / \mathrm{mL}$ MTT in culture medium for $4 \mathrm{~h}$. MTT reagent was discarded and DMSO was added. The absorbance was measured at the wavelength of $570 \mathrm{~nm}$. The data is expressed as means \pm S.E.M and obtained from three independent experiments with four replicates for each experiment. $* p<0.05, * * p<0.01$ and $* * * p<0.001$ compared with the control group. $\# p<0.05$ and \#\#\# $p<0.001$ compared with the F. pinicola ethanol extract-treated group.

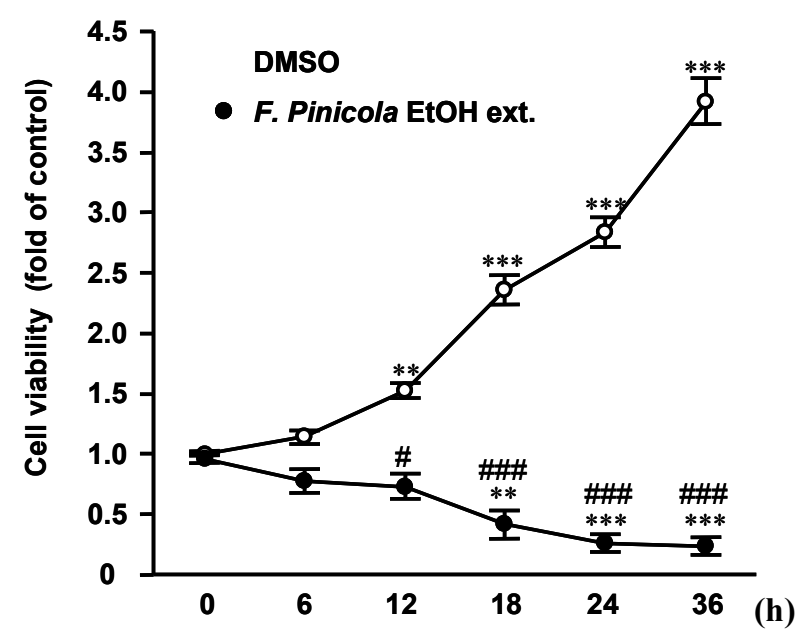

\subsection{Ethanol Extract of F. pinicola Induces Cell Apoptosis in Cancer Cells}

We further investigated the possible mechanism of the inhibitory effect on cancer cells for $F$. pinicola ethanol extracts (Figure 3). Treatment of $F$. pinicola ethanol extract increased the expression of cleaved-caspase 3 in different cancer cell lines, implying the induction of cell apoptosis. In addition, we found the increased expression of apoptosis-related proteins, such as Apaf, cleaved-caspase 3 and PARP. Treatment of S-180 cells with $F$. pinicola ethanol extract significantly and dose-dependently increased the expression of Apaf, cleaved caspase 3 and PARP (Figure 3), implying the $F$. pinicola ethanol extracts induces cell apoptosis.

\subsection{Anti-Tumor Activity of $F$. pinicola Ethanol Extract In Vivo}

To clarify the usefulness of $F$. pinicola ethanol extract as an alternative medicine for cancer therapy, mice were mice fed a diet containing $0.5 \% \mathrm{~F}$. pinicola ethanol extract. As shown in Figure 4 this significantly inhibited $46 \%$ tumor growth without causing sudden death (data not shown). There was no marked weight loss in these mice after the high dose treatment of $F$. pinicola ethanol extract (data not shown). In addition, administration of $F$. pinicola ethanol extract prolonged the survival time of S-180 cell-bearing mice (Figure 5). It was reported that the constituents of $F$. pinicola regulate hyperglycemia via either increased insulin secretion during recovery or the prevention of streptozotocin-induced pancreatic damage and there is no evidence of toxicity in $F$. pinicola extract-treated rats [9]. In this study, no significant toxicity was observed in $F$. pinicola extract-treated 
mice, consistent with the previous study [9]. Therefore, ethanol extract of $F$. pinicola may be a new alternative medicine for the treatment of cancer.

Figure 3. Ethanol extract of $F$. pinicola induced apoptosis to exert anti-tumor effect in cancer cells. Different human cancer cell lines as indicated were treated with $12.5 \mu \mathrm{g} / \mathrm{mL}$ $F$. pinicola ethanol extract for $18 \mathrm{~h}$. The cleaved-caspase 3 levels were detected by western blots (left panel). Mouse sarcoma S-180 cells were treated with $12.5 \mu \mathrm{g} / \mathrm{mL} F$. pinicola ethanol extract for $18 \mathrm{~h}$. The apoptosis-related protein expressions were detected by Western blots (middle and right panels). ${ }^{*} p<0.05$, and ${ }^{* *} p<0.01$ compared with the control group.
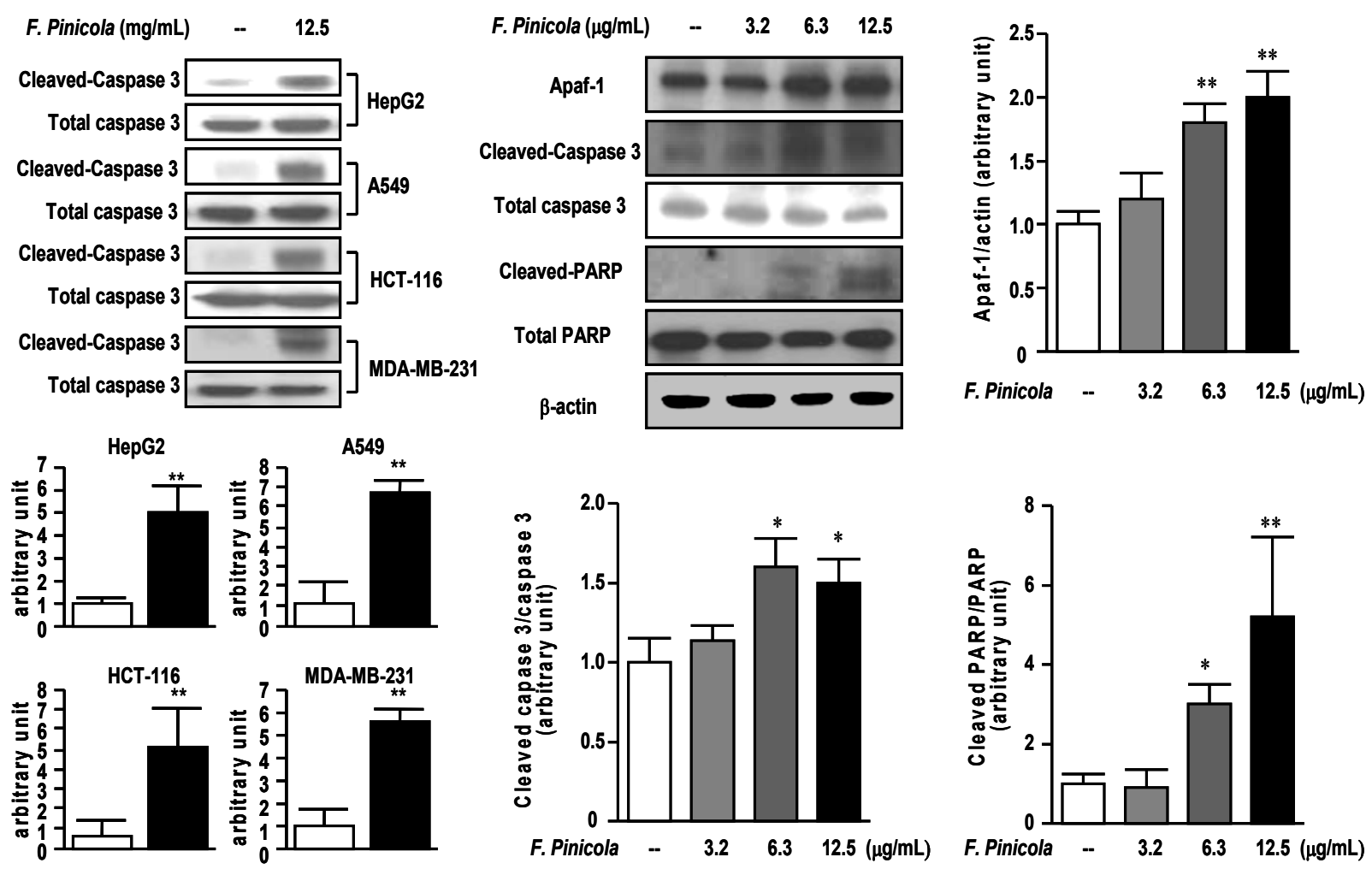

\subsection{F. pinicola Ethanol Extract Synergistically Enhances Anti-Tumor Activity of Cisplatin in S-180} Mouse Sarcoma Cells

In order to develop new therapeutic options with high efficacy and low toxicity, we tested by MTT assay the effectiveness of combining a conventional antineoplastic drug, cisplatin, with $F$. pinicola ethanol extract in the treatment of S-180 mouse sarcoma cells. We found that the use of F. pinicola ethanol extract as monotherapy reduced the viability of the S-180 cell line. Combining $F$. pinicola ethanol extract with cisplatin produced a synergistic effect and was more effective than was the use of cisplatin as monotherapy (Figure 6). Taken together, these results indicate that $F$. pinicola ethanol extract could be a potential alternative adjuvant anti-tumour medicine representing a promising approach to the treatment of some cancers in the future. 
Figure 4. Administration of $F$. pinicola ethanol extract in S-180 tumor-bearing mice decreased tumor size and prolonged the survival time of the mice. Mice were pre-treated with a diet supplemented with different doses of $F$. pinicola ethanol extract as indicated for 3 days. Solid-type sarcoma S-180 was subcutaneously injected in mice on day 0. The indicated amounts of $F$. pinicola ethanol extract were supplied for 27 consecutive days. The tumor volume was determined by direct measurement with calipers and calculated every 3-day. Results are expressed as means \pm S.E.M. $n=10 .{ }^{*} p<0.05$ and ** $p<0.01$ compared with normal chow group.

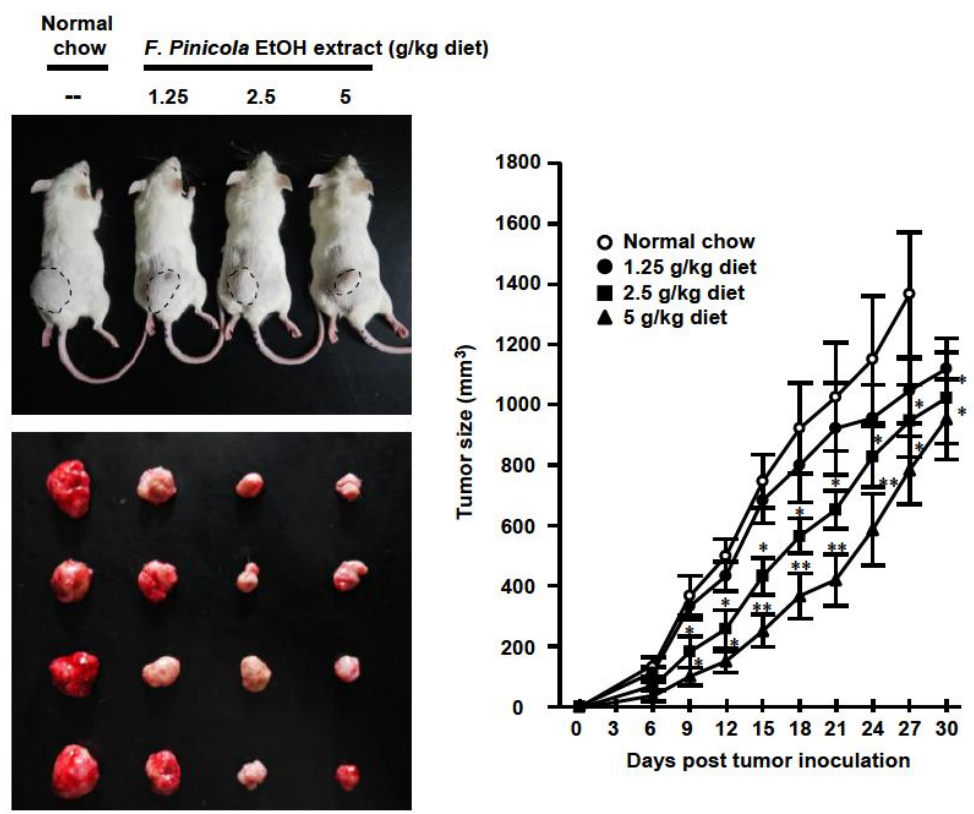

Figure 5. Administration of $F$. pinicola ethanol extract in S-180 tumor-bearing mice prolonged the survival time of the mice. Mice were pre-treated with a diet supplemented with different doses of $F$. pinicola ethanol extract as indicated for 3 days. Solid-type sarcoma 180 was subcutaneously injected in mice on day 0 . The indicated amounts of $F$. pinicola ethanol extract were supplied for 27 consecutive days. Survival times of the S-180 tumor-beaing mice were recorded after after tumor inoculation. Results are expressed as the numbers of survival animals, $n=10$.

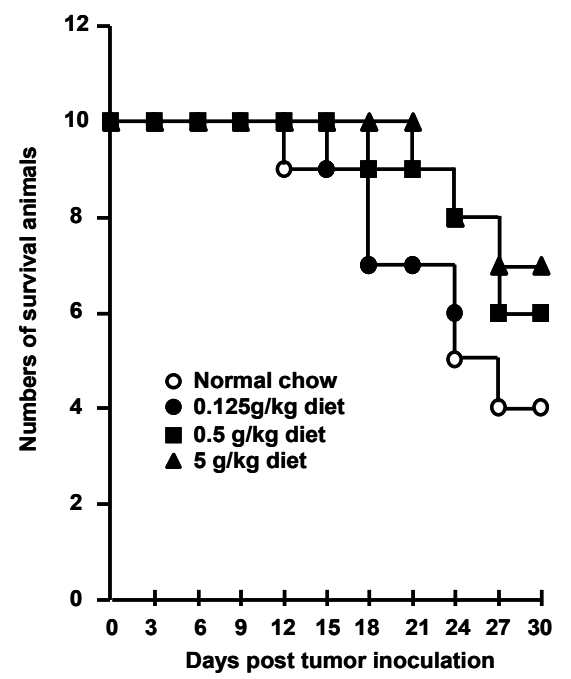


Figure 6. F. pinicola ethanol extract enhances the anti-tumor activity of cisplatin. Sarcoma S-180 cells were treated with $F$. pinicola ethanol extract, cisplatin or $F$. pinicola ethanol extract plus cisplatin at indicated doses for $24 \mathrm{~h}$. Cells were then incubated with $0.2 \mathrm{mg} / \mathrm{mL}$ MTT in culture medium for $4 \mathrm{~h}$. MTT reagent was discarded and DMSO was added. The absorbance was measured at the wavelength of $570 \mathrm{~nm}$. The data was obtained from three independent experiments with four replicates for each experiment. ${ }^{* *} p<0.01$ and *** $p<0.001$ compared with the control group. ${ }^{\#} p<0.01$ and ${ }^{\# \#} p<0.001$ compared with F. pinicola ethanol extract-treated alone group. ${ }^{\$} p<0.05$ and ${ }^{\$} p<0.01$ compared with cispltin-treated alone group.

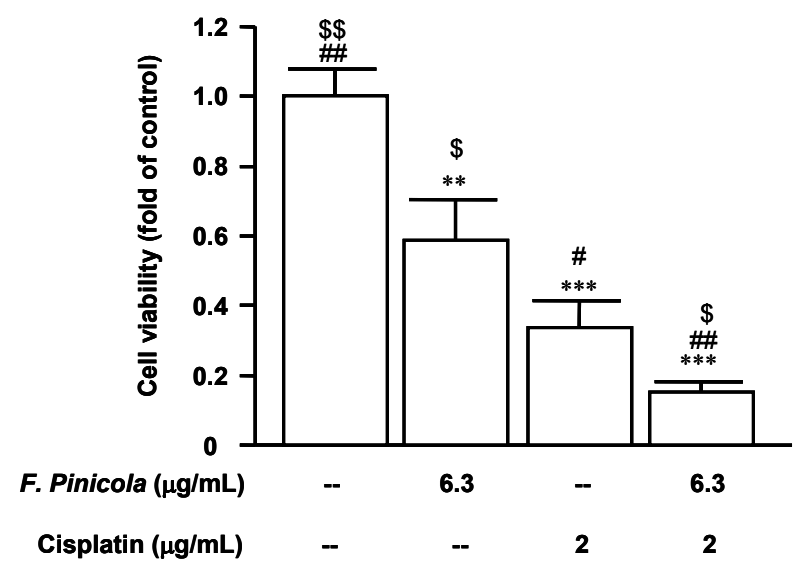

\section{Experimental}

\subsection{Plant Material and Extraction}

Different fungal fruit bodies were purchased from the Agricultural Production and Marketing Groups of the Hualien District Agricultural Research and Extension Station (Ji-An Country, Hualien County, Taiwan) in September 2011. The identification of the fungi was confirmed by macroscopic and microscopic examinations, as well as thin-layer chromatography and HPLC methods. The fungal fruit bodies were dried under shade at $25{ }^{\circ} \mathrm{C}$. The dried samples $(1 \mathrm{~kg})$ were cut into small pieces, immersed, and extracted three times with ethanol, 50\% ethanol or distilled water $(10 \mathrm{~L} \times 3)$ for $24 \mathrm{~h}$ at room temperature. After filtration, the solvent was removed by distillation under reduced pressure and the remaining solution was lyophilized to obtain a brown powder, and the samples were stored at $4{ }^{\circ} \mathrm{C}$.

\subsection{Cell Cultures}

The cancer cell lines, HepG2 and S-180 cell lines were purchased from the Bioresource Collection and Research Center (Food Industry Research and Development Institute, Hsinchu, Taiwan). HCT-116 and MDA-MB-231 are gifts from Prof. M.D. Lai, and A549 is from Prof. C.L. Wu (Department of Biochemistry and Molecular Biology, College of Medicine, National Cheng Kung University, Tainan, Taiwan). Cells were maintained in Dulbecco's modified Eagle medium (Hyclone, South Logan, UT, USA) supplemented with $10 \%$ heat-inactivated fetal bovine serum. Cell viability is determined by trypan blue staining and calculated as the number of viable cells divided by the total number of cells 
within the grids on the hemacytometer. If cells take up trypan blue, they are considered non-viable. $\%$ Viable cells $=[1.00-($ Number of blue cells/Number of total cells $)] \times 100 \%$. Cell viability should be at least $95 \%$ for healthy log-phase cultures.

\subsection{MTT Assay}

Cells $\left(5 \times 10^{4}\right.$ cells per well $)$ were seeded in a 96-well flat-bottom culture plate. After the additional treatments for indicated intervals, $100 \mu \mathrm{L}$ of $0.2 \mathrm{mg} / \mathrm{mL} 3-(4,5-$ methylthiazol-2-yl)-2,5-diphenyltetrazolium bromide (MTT, USB Corporation, Cleveland, OH, USA) was added per each well, and cells were incubated for four hours at $37{ }^{\circ} \mathrm{C}$. After incubation, the MTT reagent was discarded, and $100 \mu \mathrm{L}$ of DMSO was then added. The experiment was performed at room temperature for $20 \mathrm{~min}$. The absorbance was then measured with Multiskan GO spectrophotometer (Thermo Scientific, Waltham, MA, USA) at the wavelength of $570 \mathrm{~nm}$. The viability of control group was set as $100 \%$ and the cell viability of each tested groups was calculated by the following formula: Cell viability $(\%)=\left(\mathrm{OD}_{\text {treated }} / \mathrm{OD}_{\text {control }}\right) \times 100 \%$.

\subsection{Western Blotting}

The cells were harvested at the indicated times and lysed with a buffer containing $1 \%$ Triton X-100, $50 \mathrm{mM}$ of Tris ( $\mathrm{pH} 7.5), 10 \mathrm{mM}$ of EDTA, $0.02 \% \mathrm{NaN} 3$, and a protease inhibitor cocktail (Sigma-Aldrich, St. Louis, MO, USA). The protein concentration was determined by BCA assay kit (Pierce Biotechnology, Rockford, IL, USA). Protein lysates $(50 \mu \mathrm{g})$ were separated using 10\% SDS-polyacrylamide gel electrophoresis and transferred to a polyvinylidene difluoride membrane (Millipore, Billerica, MA, USA). The membrane was blocked at room temperature for $1 \mathrm{~h}$ in TBS-T (10 mM Tris, $150 \mathrm{mM} \mathrm{NaCl}$, and 0.05\% Tween 20, [pH 7.6]), containing 10\% skim milk, and probed with 1:1,000 primary antibodies, such as Apaf, caspase 3, PARP (Cell Signaling Technology, Beverly, MA, USA) and actin (Santa Cruz Biotechnology inc, Santa Cruz, CA, USA) at $4{ }^{\circ} \mathrm{C}$ overnight. Subsequently, the blots were washed with TBS-T and incubated with a 1:5,000 dilution of horseradish peroxidase-conjugated secondary antibodies at room temperature for $1 \mathrm{~h}$. The protein bands were visualized using Immobilon ${ }^{\mathrm{TM}}$ (Millipore). Actin was used as the internal control. The relative signal intensity was quantified using ImageJ software from W. Rasband (National Institutes of Health, Bethesda, MD, USA).

\subsection{S-180 Bearing Animal Model}

Eight-week-old BALB/c male mice were purchased from the Animal Center of National Cheng Kung University Medical College. Mice were housed in a temperature $\left(25 \pm 1{ }^{\circ} \mathrm{C}\right)$ and humidity $(60 \% \pm 5 \%)$ controlled room and kept on a 12:12 light-dark cycle (light on at 0600). The animal procedures were performed according to the Guide for the Care and Use of Laboratory Animals of the National Institutes of Health, as well as the guidelines of the Animal Welfare Act. The mice were fed with a chow diet supplied with $1.25,2.5$, and $5 \mathrm{~g} / \mathrm{kg}$ diet $F$. pinicola ethanol extract for 3 days, and then S-180 tumor cells $\left(10^{7}\right.$ cells $\left./ 200 \mu \mathrm{L}\right)$ were implanted subcutaneously into the left hind groin of the experimental mice followed by a previous study [20]. 


\subsection{Statistical Analysis}

Data are expressed as means \pm S.E.M. Student's $t$-test was used to determine the source of significant differences where appropriate. Significance was declared when the $p$ value was less than 0.05 .

\section{Conclusions}

Ethanol extracts of different fungal species show significant inhibitory effects on cancer cells as compared with the water extracts. In addition, among the different fungi species, $F$. pinicola ethanol extract induces cancer cell apoptosis to display a strong anti-cancer activity in vitro and in vivo. $F$. pinicola ethanol extract may serve as a potential complementary and alternative medicine to treat patients suffering from cancer.

\section{Acknowledgments}

This work was supported by the National Science Council of Taiwan (NSC 102-2314-B-006-007 and NSC 102-2314-B-006-008), Taiwan.

\section{Author Contributions}

Hung-Tsung $\mathrm{Wu}$ and Chih-Jen Chang were responsible for designing and conducting the study, interpreting the data, and writing the manuscript. Feng-Hwa $\mathrm{Lu}, \mathrm{Yu}-\mathrm{Chu} \mathrm{Su}$, Horng-Yih Ou, and Hao-Chang Hung contributed to data collection, analysis, and interpretation. Jin-Shang Wu and Yi-Ching Yang contributed to data interpretation.

\section{Conflicts of Interest}

The authors declare no conflict of interest.

\section{References}

1. Zheng, R.; Jie, S.; Hanchuan, D.; Moucheng, W. Characterization and immunomodulating activities of polysaccharide from Lentinus edodes. Int. Immunopharmacol. 2005, 5, 811-820.

2. Yuen, J.W.; Gohel, M.D. Anticancer effects of Ganoderma lucidum: A review of scientific evidence. Nutr. Cancer 2005, 53, 11-17.

3. Kim, H.J.; Chang, W.K.; Kim, M.K.; Lee, S.S.; Choi, B.Y. Dietary factors and gastric cancer in Korea: A case-control study. Int. J. Cancer 2002, 97, 531-535.

4. Hara, M.; Hanaoka, T.; Kobayashi, M.; Otani, T.; Adachi, H.Y.; Montani, A.; Natsukawa, S.; Shaura, K.; Koizumi, Y.; Kasuga, Y.; et al. Cruciferous vegetables, mushrooms, and gastrointestinal cancer risks in a multicenter, hospital-based case-control study in Japan. Nutr. Cancer 2003, 46, 138-147.

5. Zhang, M.; Huang, J.; Xie, X.; Holman, C.D. Dietary intakes of mushrooms and green tea combine to reduce the risk of breast cancer in Chinese women. Int. J. Cancer 2009, 124, 1404-1408.

6. Rosecke, J.; Pietsch, M.; Konig, W.A. Volatile constituents of wood-rotting basidiomycetes. Phytochemistry 2000, 54, 747-750. 
7. Keller, A.C.; Maillard, M.P.; Hostettmann, K. Antimicrobial steroids from the fungus Fomitopsis pinicola. Phytochemistry 1996, 41, 1041-1046.

8. Zjawiony, J.K. Biologically active compounds from Aphyllophorales (polypore) fungi. J. Nat. Prod. 2004, 67, 300-310.

9. Lee, S.I.; Kim, J.S.; Oh, S.H.; Park, K.Y.; Lee, H.G.; Kim, S.D. Antihyperglycemic effect of Fomitopsis pinicola extracts in streptozotocin-induced diabetic rats. J. Med. Food 2008, 11, 518-524.

10. Yoshikawa, K.; Inoue, M.; Matsumoto, Y.; Sakakibara, C.; Miyataka, H.; Matsumoto, H.; Arihara, S. Lanostane triterpenoids and triterpene glycosides from the fruit body of Fomitopsis pinicola and their inhibitory activity against COX-1 and COX-2. J. Nat. Prod. 2005, 68, 69-73.

11. Usui, T.; Hosokawa, S.; Mizuno, T.; Suzuki, T.; Meguro, H. Investigation of the heterogeneity of heterogalactan from the fruit bodies of Fomitopsis pinicola, by employing concanavalin A-Sepharose affinity chromatography. J. Biochem. 1981, 89, 1029-1037.

12. Franceschi, S.; Wild, C.P. Meeting the global demands of epidemiologic transition-The indispensable role of cancer prevention. Mol. Oncol. 2013, 7, 1-13.

13. Liu, Y.W.; Gao, J.L.; Guan, J.; Qian, Z.M.; Feng, K.; Li, S.P. Evaluation of antiproliferative activities and action mechanisms of extracts from two species of Ganoderma on tumor cell lines. J. Agric. Food Chem. 2009, 57, 3087-3093.

14. Bishayee, A.; Ahmed, S.; Brankov, N.; Perloff, M. Triterpenoids as potential agents for the chemoprevention and therapy of breast cancer. Front. Biosci. 2011, 16, 980-996.

15. Wasser, S.P. Medicinal mushrooms as a source of antitumor and immunomodulating polysaccharides. Appl. Microbiol. Biotechnol. 2002, 60, 258-274.

16. Borchers, A.T.; Krishnamurthy, A.; Keen, C.L.; Meyers, F.J.; Gershwin, M.E. The immunobiology of mushrooms. Exp. Biol. Med. 2008, 233, 259-276.

17. Mattila, P.; Suonpaa, K.; Piironen, V. Functional properties of edible mushrooms. Nutrition 2000, 16, 694-696.

18. Zaidman, B.Z.; Yassin, M.; Mahajna, J.; Wasser, S.P. Medicinal mushroom modulators of molecular targets as cancer therapeutics. Appl. Microbiol. Biotechnol. 2005, 67, 453-468.

19. Petrova, A.; Popov, S.; Gjosheva, M.; Bankova, V. A new triterpenic alcohol from Fomitopsis pinicola. Nat. Prod. Res. 2007, 21, 401-405.

20. Bezerra, D.P.; Castro, F.O.; Alves, A.P.; Pessoa, C.; Moraes, M.O.; Silveira, E.R.; Lima, M.A.; Elmiro, F.J.; Costa-Lotufo, L.V. In vivo growth-inhibition of Sarcoma 180 by piplartine and piperine, two alkaloid amides from Piper. Braz. J. Med. Biol. Res. 2006, 39, 801-807.

Sample Availability: Samples of the water or ethanol extracts of Fomitopsis pinicola (F. pinicola), Ganoderma sinense, Fomitopsis officinalis, Polyporus melanopus, and Taiwanofungus camphorates are available from the authors.

(C) 2014 by the authors; licensee MDPI, Basel, Switzerland. This article is an open access article distributed under the terms and conditions of the Creative Commons Attribution license (http://creativecommons.org/licenses/by/3.0/). 